\title{
Effect of Different Musical Tempo on Post-Exercise Recovery in young adults.
}

\author{
Dr. Sheetal Diliprao Bhavsar ${ }^{1}$, Dr. Rahul S. Abhange ${ }^{2}$, Dr. Sayeeda Afroz ${ }^{3}$ \\ ${ }^{1,3}$ (Department of Physiology, Government Medical College, Latur, Maharashtra, India) \\ ${ }^{2}$ (Department of Pathology, GMC, Latur, Maharashtra, India)
}

\begin{abstract}
The study was about the effect of music and different musical tempo on post-exercise recovery time following moderate exercise as there is very little information about effect of music on time taken for postexercise recovery. Sixty volunteers (30 male, 30 female) subjected to isotonic exercise i.e. Harvard's step test, on three consecutive days, followed by rest in silence on first day, rest by hearing slow music on second day and rest by hearing fast music on third day. Parameters such as Pulse rate and blood pressure, were measured at predetermined intervals. The ANOVA test showed that with slow music, recovery time of systolic blood pressure

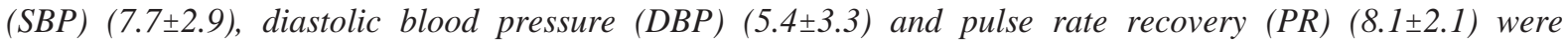
significantly faster when compared to both no music and fast music. The study concluded that music hastens post-exercise recovery and slow music has greater relaxation effect than fast or no music, recovery time was independent of the gender and individual music preference.
\end{abstract}

Key words: musical tempo, post-exercise, recovery, young adults.

\section{Introduction:}

Physical exercise, an essential part of maintaining a happy and healthy lifestyle, is associated with changes in cardio-respiratory parameters and increases psychological stress and exertion. Following exercise, these parameters return to the resting values once the $\mathrm{O}_{2}$ debt is recovered [1]. But it is not without risk of injury. To minimize these risks and perform optimally the next time you exercise, you must allow your body to recover. Exercise recovery involves a number of post-exercise steps that are essential for any exercise regime. It does not take long or require much effort, but it is often neglected.

There are a lot of things around that can improve recovery, and that relates to our physical well-being with the mental side of things. These are like post-exercise rest, sleep, massage, nutrition, hydration, cryotherapy, etc. In addition, music may be the one of the way to improve the same.

Music has long been known to affect the human body, with certain sounds influencing health, character, mood and consciousness of the listener. Effects of music prior to exercise and sport have been studied extensively. Pre-task music has been shown to act as an effective stimulant that can optimize arousal level and physiological states [2]. Effects of music during physical activity have also been investigated thoroughly.

Although the role of such music is typically motivational, it may also serve to promote relaxation and efficiency in long-duration, repetitive activities such as distance running. The effects of post-exercise music to aid recovery, competition or injury- are now beginning to receive attention. So the recent study emphasizes the value of music in lowering stress [3] and its role in enhancing the exercise performance [4] by incorporating music in exercise regimen.

The objectives of the study were:

\section{Aims And Objectives:}

2.1) To study the effect of exercise on cardiovascular autonomic functions.

2.2) To study the effect of different musical tempo i.e. slow and fast music on post-exercise recovery time.

2.3) To study the gender differences in the effect of different musical tempo on post-exercise recovery time.

\section{Material And Methods:}

Preclinical medical students $(\mathrm{M}=30, \mathrm{~F}=30)$ of G.M.C., Latur were selected as the subjects. The selected subjects were interested in music and were not physically challenged.

An informed consent was obtained. A questionnaire was filled in by the subjects before testing to confirm that each subject was a non-smoker, with no personal history of allergy or any cardio- respiratory disease, etc. The subjects were assessed during the same time of year and at the same time of day to avoid possible seasonal and diurnal variation. It was ensured that all subjects were normal at the time of testing and at least 6 weeks prior to it. They were also asked not to exercise strenuously for 6 hours before the test. 
Age was obtained from the date of birth. Body height in cms was taken in erect standing position without shoes with metallic tape. Body weight was recorded in $\mathrm{kgs}$ on a weighing machine with subject in his normal clothing without shoes.

After 30 minutes of rest in laboratory basal readings were recorded. The subject was allowed to do isotonic exercise for 6 minutes i.e. Harvard's step test for 3 consecutive days. Then subjects were allowed to rest in silence on the first day, rest by hearing slow music on second day and rest by hearing fast music on third day. After each exercise session the following parameters were recorded every 2 minutes until these returned to resting values. The mobile with headphones was used for hearing music (Indian traditional classical music and western style) of their own choice.

- $\quad$ Pulse rate (beats/min) : Radial pulse with three fingers

- Systolic blood pressure ( $\mathrm{mmHg}$ )

- Diastolic blood pressure $(\mathrm{mmHg})$

BP was measured with sphygmomanometer and stethoscope in standing position to eliminate the effect of posture both before and after exercise.

The data was analysed statistically using ANOVA test.

\section{Observation And Results:}

Sixty healthy $(M=30, F=30)$ preclinical medical students were selected for the study. Age group of subjects was between 17 to 19 years. Mean height of the male was $169.5 \mathrm{cms}$ and female was $157 . .25 \mathrm{cms}$. Mean weight of women was $53.9 \mathrm{kgs}$ and of men was $62.3 \mathrm{kgs}$. The height and weight were significantly greater in men $(\mathrm{P}<0.05)$ (Table I). There was no significant difference between the ages of men and women.

Immediately after exercise, there was increase in SBP and PR and reduction in DBP. The systolic blood pressure (SBP) (7.7 \pm 2.9$)$, diastolic blood pressure (DBP) (5.4 \pm 3.2$)$ and pulse rate recovery (PR) (8.1 \pm 2.1$)$ were significantly faster as compared to recovery time of fast music and without music $(\mathrm{P}<0.05)($ Table IV and Graph 1).

Table I shows the physical characteristics like age, body weight, height, SBP, DBP and PR of subjects.

\begin{tabular}{|l|l|l|l|l|l|}
\hline Sr. & & Men & Women \\
\hline No. & Parameters & Mean & S.D. & Mean & S.D. \\
\hline 1 & Age (years) & 17.66 & 0.59 & 18.33 & 0.69 \\
\hline 2 & Height (cms) & 169.5 & 6.38 & 157.25 & 6.12 \\
\hline 3 & Weight $(\mathrm{kgs})$ & 62.3 & 10.66 & 53.9 & 8.25 \\
\hline 4 & SBP $(\mathrm{mmHg})$ & 118.6 & 6.7 & 110 & 4.2 \\
\hline 5 & DBP $(\mathrm{mmHg})$ & 70.1 & 7.0 & 62.1 & 4.3 \\
\hline 6 & PR (bpm $)$ & 76.5 & 6.8 & 78.3 & 4.5 \\
\hline
\end{tabular}

Table II shows pre-exercise values of parameters i.e. at rest without music.

\begin{tabular}{|l|l|c|c|c|c|}
\hline \multirow{2}{*}{ Sr. No. } & \multirow{2}{*}{ Parameters } & \multicolumn{3}{|c|}{ Men } & \multicolumn{3}{c|}{ Women } \\
\hline 1 & SBP $(\mathrm{mmHg})$ & Mean & S. D. & Mean & S.D. \\
\hline 2 & DBP $(\mathrm{mmHg})$ & 118.6 & 6.7 & 110 & 4.2 \\
\hline 3 & PR (bpm $)$ & 70.1 & 7.0 & 62.1 & 4.3 \\
\hline
\end{tabular}

Table III shows values of parameters at rest with slow music.

\begin{tabular}{|l|l|c|c|c|c|}
\hline \multirow{2}{*}{ Sr. No. } & \multirow{2}{*}{ Parameters } & \multicolumn{2}{|c|}{ Men } & \multicolumn{2}{c|}{ Women } \\
\cline { 2 - 6 } & Mean & S. D. & Mean & S.D. \\
\hline 1 & SBP (mmHg) & 118.3 & 5.5 & 110 & 3.8 \\
\hline 2 & DBP (mmHg) & 70.1 & 6.0 & 61.8 & 4.1 \\
\hline 3 & PR (bpm ) & 75.0 & 6.3 & 78.0 & 3.5 \\
\hline
\end{tabular}


Table IV shows values of parameters at rest with fast music

\begin{tabular}{|l|l|c|c|c|c|}
\hline \multirow{2}{*}{ Sr. No. } & & \multicolumn{3}{|c|}{ Men } & \multicolumn{2}{c|}{ Women } \\
\hline 1 & Parameters & Mean & S. D. & Mean & S.D. \\
\hline 2 & DBP $(\mathrm{mmHg})$ & 118.5 & 6.3 & 110 & 3.9 \\
\hline 3 & PR $(\mathrm{mmHg})$ & 70.1 & 6.2 & 61.9 & 4.1 \\
\hline
\end{tabular}

Table V shows effects of slow and fast music on post-exercise recovery time.

\begin{tabular}{l|l|c|c|c|c|c|c|c|}
\multirow{2}{*}{$\begin{array}{l}\text { Sr. } \\
\text { No. }\end{array}$} & \multirow{2}{*}{ Parameters } & \multicolumn{2}{|c|}{ No music } & \multicolumn{3}{c|}{ Slow music } & \multicolumn{3}{c}{ Fast music } \\
\cline { 2 - 10 } & Mean & S. D. & Mean & S.D. & Mean & SD \\
\hline 1 & SBP (mmHg) & 10.5 & 2.6 & 7.7 & 2.9 & 9.2 & 2.5 \\
\hline 2 & DBP (mmHg) & 6.9 & 3.2 & 5.4 & 3.2 & 6.0 & 3.4 \\
\hline 3 & PR (bpm $)$ & 12.3 & 3.5 & 8.1 & 2.1 & 9.7 & 2.3 \\
\hline
\end{tabular}

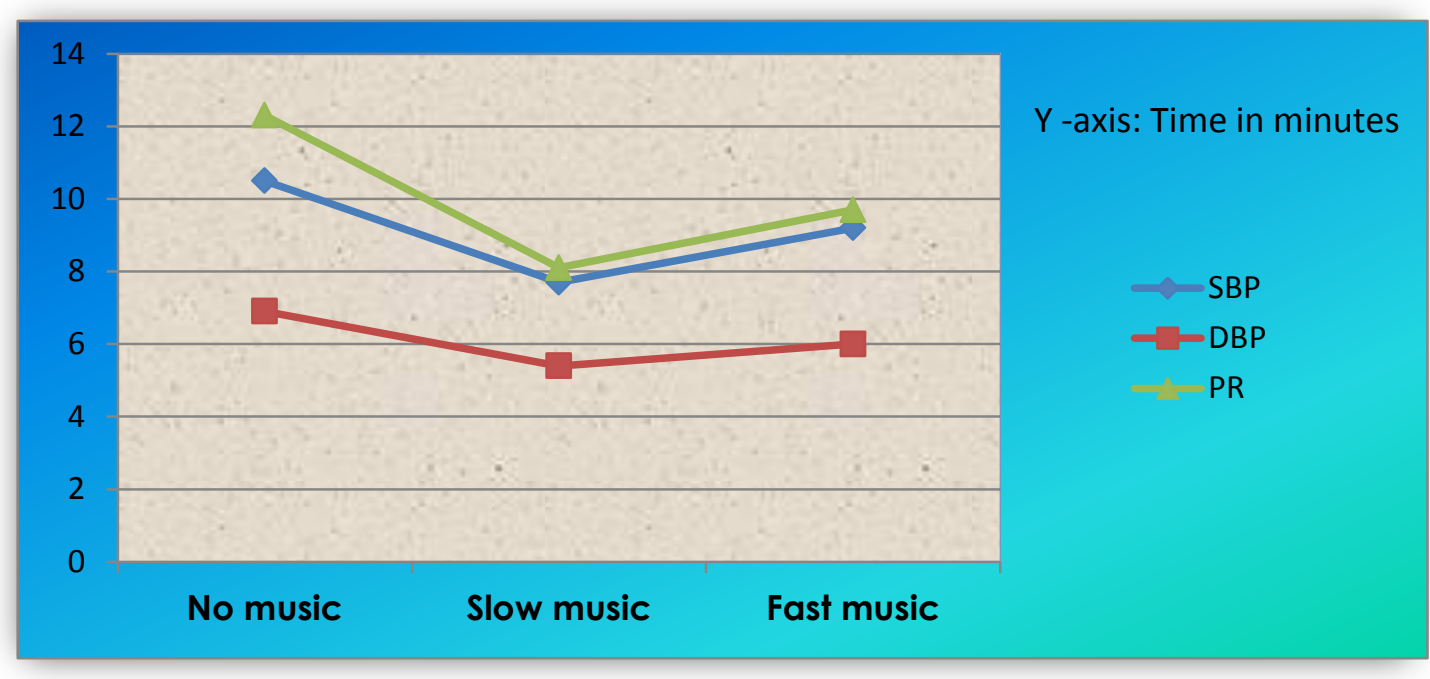

Graph 1

\section{Discussion:}

The present study shows that relaxation with music after a bout of acute moderate exercise caused faster recovery of physiological parameters like BP and PR in comparison with silence. The effect of slow and fast music was different i.e. with slow music recovery was faster than with fast one. This is probably because slow music reduced the arousal, leaving the subject in a state of relaxation [5]. The individual preference of the music had no effect on the relaxation time in both males and females. Music reduced muscular and mental tension and thereby reduced sympathetic stimulation as observed in some studies. It is consistent with other study which proved that music has the potential to reduce physiological indicators of anxiety including pulse rate and blood pressure [6,7]. There is decreased plasma catecholamine concentration when relaxation is accompanied by music [8]. These factors may caused recovery of the pulse rate and blood pressure to baseline earlier than relaxation in the absence of music.

In order to get fitter or improve in sport, the body needs to be exposed to stresses (i.e. training or exercise), once this has happened, the body then needs time to adapt to the stresses and for this there must be a period of recovery. As work alone is not enough to produce the best results; you need time to adapt to training stress. To encourage adaptation to training, it is important to plan recovery activities that reduce residual fatigue. Rest and recovery are important in prevention of injuries.

Bishop et al. define recovery as the ability to meet or exceed performance in a particular activity. The recovery after exercise is essential to muscle and tissue repair, strength building as well as for optimal performance and improvement. If rate of recovery is improved, higher training volumes and intensities are possible without detrimental effects of overtraining [9]. Jeffreys continues that factors of recovery include 1) normalization of physiological functions (e.g., blood pressure, cardiac cycle), 2) return to homeostasis (resting cell environment), 3) restoration of energy stores (blood glucose and muscle glycogen), and 4) replenishment of cellular energy enzymes (i.e. phosphofructokinase a key enzyme in carbohydrate metabolism) [10]. 
Music doesn't just motivate you during a tough workout, it can aid recovery, too. Folks who ran hard for six minutes, then listened to up-tempo tunes, had a faster reduction in lactic acid (the stuff that causes sore muscles), compared with those who didn't listen to any music, one study found [11].

Listening to music during recovery can unleash myriad benefits. In mild to moderate exercise, music improves the exercise performance and reduces the perceived exertion. On the contrary, in severe exercise, music has the potential to maximize the motivational and affective components but does not enhance the performance quality [12].

Motivational music had a significant effect (compared to no music) on number of steps, perceived rate of exertion and blood lactate. Using rhythm beats only (derived from the original music) also had significant effect on number of steps and blood lactate. Music used was previously shown to enhance recovery [13]. The music has a psycho-physiological effect. There was a scientific inquiry that revealed a psycho-physiological influence of music on the process of recovery by regulation of the arousal mechanism and acquisition of motor skills [14]. Further, the tempo of music has its own influence on exercise.

The relaxing music has better effects on the rehabilitation of cardiovascular, central, musculoskeletal and psychological fatigue and the promotion of the regulatory capability of the kidneys. The music used for this study was 'Acupuncture on the Mind' [15]. Music provides greater reduction in blood lactate (compared to no music), thereby potentially reducing stress and speeding post-exercise recovery. They do not clarify what they used as "relaxing music" [16].

Music is a well known relaxation technique from times immemorial. It brings the mind and body kind of down to a more static state. Listening to music is a complex phenomenon, involving psychological, emotional, neurological and cardio-respiratory changes' as well as behavioural modifications of breathing. So it helps people restore the heart rate to resting state. It helps the body do that in a nice controlled manner. On top of that, it just can help reduce stress $[17,18]$.

Despite the type of music used, most (if not all) studies agree that significant benefits occur after listening to music for 15 minutes post exercise. In some cases, exercise participants were lying down while listening to the music. Personal trainers, sports coaches, physical therapists, etc., can incorporate 15 minutes of music therapy at the end of an intense training session to aid participants' recovery between sessions.

Savitha D. et al concluded that music of slow tempo is a good tool for relaxation following a bout of physical exercise. Slow music hastened the recovery of physical parameters like pulse rate and blood pressure. It also had an affective component in that it caused a subjective feeling of faster recovery from exertion when compared to no or fast music. The individual music preferences and gender difference had no significant influence on the effect of music on the relaxation time [19].

The study concludes that,

\section{Conclusion:}

6.1) After moderate exercise, there was increase in SBP and PR while DBP was reduced.

6.2) Post-exercise recovery was faster with slow music than with fast music as well as with no music and the individual preference of the music had no effect on the relaxation time in both males and females.

6.3) There was no significant difference among the two genders in recovery time of SBP, DBP and PR with two types of music and without music.

The introduction of music makes the process of recovery for sportsmen more effective. So music can be introduced in ones exercise regimen to improve recovery, in turn, to exceed performance in a particular activity.

\section{References:}

[1]. Masters KS, Ogles BM. Associative and dissociative cognitive strategies in exercise and running: 20y later, what do we know? Spot Phychol1998; 12: 253-270.

[2]. Terry, P.C. \& Karageorghis, C.I. (2011). Music in sport and exercise. In T. Morris \& P. C. Terry (Eds.), The new sport and exercise psychology companion (pp. 359-380). Morgantown, WV: Fitness Information Technology.

[3]. Szmedra L, Bacharach DW. Effects of music on perceived exertion, plasma lactate, norepinephrine and cardiovascular hemodynamics during treadmill running. J Sports Med 1998; 19: 32-37.

[4]. That MH, Kenyon GP, Schauer ML et al. The connection between rhythmicity and brain

[5]. function: implications for therapy of movement disorders. IEEE Eng Med Biol Mag 1999; 18: 101-108.

[6]. Jane ME. Cardiovascular exercise physiology. In: Stanley P. Brown, Wayne C. Miller, Jane M. Eason. Exercise physiology- Basis of human movement in health and disease. $1^{\text {st }}$ ed. Lippincott Williams and Wilkins: USA, 2006: 184-193.

[7]. Yamamoto T, Ohkuwa T. Effects of pre-exercise listening to slow and fast rhythm music on supramaximal cycle performance and selected metabolic variables. Arch Physiol Biochem 2003; 111: 211-214.

[8]. Smolen D, Topp R, Singer L. The effect of self selected music during colonoscopy on anxiety, heart rate, and blood pressure. Appl Nurs Res 2002; 15: 126-136.

[9]. Mackey M, Rocker L, Stork T. Immediate physiological responses of healthy volunteers to different types of music: cardiovascular, hormonal and mental changes. Eur J Appl Physiol Occup Physiol 1994; 68: 451-459.

[10]. Bishop, P.A, Jones E., \& Woods A.K. (2008). Recovery from training: a brief review. Journal of Strength and Conditioning Research., 22(3):1015-1024.9. 
[11]. Jeffreys, I. (2005). A multidimensional approach to enhancing recovery. Strength and Conditioning Journal. 27(5): 78-85. As reported in the April 2013 issue of Health magazine

[12]. Tenenbaum G, Lidor R, Lavyan N ; The effect of music type on running perseverance and coping with effort sensations. Psychology of Sport and Exercise 2004; 5: 89-109.

[13]. Eliakim, M., Bodner, E., Meckel, Y., Nemet, D., Eliakim, A., Netanya, I., \& Eliakim, A. (2012). Effect of rhythm on the recovery from intense exercise. The Journal of Strength \& Research. http://www.ncbi.nlm.nih.gov/pubmed/22692126

[14]. Januszewki M., Podstawy muzykoterapii, Lodz, 1997.-282 s. Karageorghis, C. I., Jones, L., \& Stuart, D. P. (2008). Psychological effects of music tempi. International Journal of Sports Medicine, 29, 613-619.

[15]. Jing, L., \& Xudong, W. (2008). Evaluation on the effects of relaxing music on the recovery from aerobic exercise-induced fatigue. Journal of sports medicine and physical fitness, 48(1), 102-106. http://www.ncbi.nlm.nih.gov/pubmed/18212717

[16]. Ghavam-Bakhtiar, R., Nikbakht, H., Ziaee, N., \& Mohammadi, M. (2012). The effect of relaxing music on changes in blood lactate level during recovery following a maximal exercise session in young female athletes. International Journal of Sport Studies, 2(9). http://ijssjournal.com/wp-content/uploads/2012/11/432-4351.pdf

[17]. Orem J, TrotterRH. Behavioral control of breathing. News Physiology Sci. 1994; 9: 228-232.

[18]. Shea SA: Behavioural and arousal-related influences on breathing in humans. Exp Physiology; 1996; 81: 1-26

[19]. Savitha D, Mallikarjuna Reddy N, Chythra Rao: Effect of different musical tempo on post-exercise recovery in young adults; Indian journal of physiology and pharmacology; 2010; 54(1); 32-6. 